\title{
School Libraries' Network: a report on a direct accompaniment experience
}

\author{
Elsa Conde \\ Lucília Santos \\ João Afonso \\ José Saro \\ Ministry of Education \\ School Libraries' Network \\ Portugal
}

\begin{abstract}
School Libraries' Network (SLN) integrates 1650 libraries, directed by school formed teams. They must accomplish a wide and complex work, which demands their integration both into school and the community.

SLN fast growth conducted to the need of providing technical support to schools. In 2004, this Program started to designate, in different areas, qualified teachers to accompany the teams which run school libraries.

Being a recent experience its results cannot be fully evaluated.

Nevertheless, SLN monitorship and the feedback from schools and other partners have been showing the importance of this initiative.
\end{abstract}

\section{School Libraries' Network Program}

In the last decades, we have been witnessing a wide range of big transformations, which shape the emergence of a new society, related to a change of paradigm and commonly called Society of Information.

This society, mostly shaped by the development of information and communication technologies, presents new challenges to schools, which aim at providing new abilities and literacies to children and youngsters in order to enable them to perceive and process information, build knowledge, solve problems and learn throughout life.

To answer these questions, School must be rethought in the way of adopting new forms of organization and educational practices which allow all children and youngsters to learn with success, whose achievement depend upon an environment characterized by articulated resources and strategies, totally different from a traditional teacher-centred teaching, based on school manuals.

School libraries go along with this general aim of changing, performing a catalytic role in it, by enabling, through access to information and different languages, new forms of educational practices and knowledge production.

In this sense, the development of school libraries must be understood as a strategic investment, essential to a solid personal education and formation and to a citizenship practice which needs to be more and more effective. 
In Portugal, the School Libraries’ Network Program is the most recent movement in order to support the creation of new libraries and the change of traditional school libraries into open, attractive and functional centres of resources, capable of assuming this role.

The School Libraries' Network Program is the result of a common initiative from the Ministry of Education and the Ministry of Culture and it was created in 1996, in accordance with a previous study which presents the principles and lines of guidance which would inspire it, namely:

- school libraries are basic resources of the educational system, with an unquestionable role in what concerns reading, literacy, acquisition of information abilities and cultural deepness, in general;

- each library must constitute itself as a free-access multimedia educational resources centre, aimed at the consultation and production of documents in several supports;

- school libraries are fundamental centres of schools' educational organization and essential instruments to the development of curricula, connected with teaching practices and non- -curricula activities, as well as free time sparing;

- the development of a school library must be understood as an endogenous process, also stimulated and sustained from the outside, and as an organizational innovation able to produce changes in the school itself, being, in this way, strictly connected to the school's educational project;

- in order to achieve all this goals, libraries must be characterized by several conditions: a space and an equipment adjusted to the diversity of their functions, a documental fund adjusted to the interests and needs of school community, a team of teachers and qualified technicians and their own budget provision ${ }^{\text {ii }}$.

The development of this Program, which is ruled by a co-ordinator cabinet, created to perform this role, is based upon a strong cooperation between, on one hand, the Ministry of Education and its Educational Region Directions (which tutor Basic and Secondary Schools) and, on the other hand, by Town Halls (responsible for Pre-School and Primary Education) ${ }^{\text {iii }}$ and their Municipal Libraries (ML), as long as possible in accordance with a specific Support Service to School Libraries ${ }^{\text {iv }}$.

Until the end of 2005, SLN integrated 1651 schools, 733 of them $1^{\text {st }}$ Cycle Basic Schools (equivalent to $10 \%$ of the total number of schools of this Educational Cycle in Portugal) and 918 from other educational cycles (corresponding to $75 \%$ of the total number of schools of Second and Third Educational Levels and Secondary Schools in Portugal). Nevertheless, the analysis of these figures must take into account the nature of the present $1^{\text {st }}$ Cycle Schools and Pre-Schools’ Net, which integrates a wide number of rural and dispersed establishments, with very few students, which is presently facing a process of redistribution and reconversion. In response to this situation, the SLN Program has been implementing different support measures, according to different rhythms and adjusted to each reality: creation of school libraries, in the case of schools with 100 or more students, whose installations are a priority; creation of small libraries, known as Packages, and Itinerant Groups, aimed at providing library services to smaller Primary Schools, which, according to the above parameters, would otherwise be excluded from library resources.

The direct investment performed by the SLN Program was, until the end of 2005, of circa 28 million Euros. 
This Program's action has been developing in several areas, the most important being:

- annual creation of applications aimed at schools of all educational cycles in order to support projects, including interventions in what concerns installations, furniture, equipments and management software acquisition and documental funds' acquisition and maintenance;

- creation, since the previous year, of a Merit Application to identify, promote and spread good practices in different areas of activity concerning school libraries;

- recruitment of human resources to the libraries of schools which belong to the SLN Program, by means of attributing to Second and Third Cycles Basic Schools and Secondary Schools a time credit of 8 hours per week to the supervisors of the teams responsible for each school library and the designation of a supervisor teacher to $1^{\text {st }}$ Cycle Schools or groups of schools, defined case by case, according to the number of students and schools' geographical location. In this school year (2005-2006) $1^{\text {st }}$ Cycle Schools were given 233 detachments according to these conditions. The policy of the Ministry of Education in what concerns these resources sustains, according to this, a profile of abilities based upon a double qualification of the supervisors, through the acquisition of extra-capacities which allow these professionals to assume themselves as librarian-teachers;

- contact with proper qualifying entities (Universities, Upper Education Schools, Training Centres, Associations, etc), in order to increase and vary the offer of qualification in school libraries, the libraries' supervisor teachers, the teams of teachers created inside the schools to support the supervisor and the functioning of those libraries, other staff which also integrate those teams, the school management directors and teachers in general, concerning both initial and continuous and specialised qualification;

- creation of documents and tools to spread information, qualification and exchange of experiences between schools and other entities and professionals which work with SLN (giving preference to on-line contacts, through the SLN site, e-mail, lists...);

- participation in meetings, seminars, conferences and other events, both national and international, in order to strengthen the SLN, and make it known at the same time.

Beyond these measures, SLN Program has been significantly investing in the improvement of the technical an educational support provided to the schools belonging to this Program, putting at their disposal qualified teachers to support and accompany both libraries and their work with other partners (Educational Region Directions ${ }^{\mathrm{v}}$, Municipal Libraries, Training Centres, etc.).

\section{Direct Accompaniment of School Libraries}

Since its creation, in 1996, the SLN Program has thought about the importance of accompanying school libraries, which was done, up to 2004, in a differentiated way, by Educational Region Directions - Technical and Educational Services and, occasionally, by some Municipal Libraries and their Support Service to School Libraries, when they existed.

This kind of support gave response to school libraries’ needs, especially at the beginning of the implementation of this program, when it urged to create new libraries and modernize those which already existed. But, because it was a program which was being constantly improved considering not only the number of schools but also the steps needed to accomplish the projects established, the lack of a specialized accompaniment became obvious. In this sense, and according to the process of establishment and creation of local nets, the aim was to offer schools the possibility to operate a qualitative step illustrated by a more efficient management of their resources, creation of new services and more effective 
programs to support educational and literacy promoting activities and an exploration of new means of cooperation between schools/groups of schools and other entities.

Keeping this in mind, in 2004, the SLN Program started the designation of a group of teachers with extra qualification on library studies and experience in conducting projects in school libraries, creating a team of direct accompaniment. This initiative, conducted and supervised by the SLN Cabinet, takes mostly place in geographical areas which, due to their interiority and isolation, reveal in a more relevant way their need of technical support, or where the high number and density of schools scarcely allowed Educational Region Directions or Support Service to School Libraries alone to provide a wide and more effective accompaniment and support to schools.

As we can see, it was not a replacement of regional/local entities, but a complement of their efforts, in order to contribute to the improvement of the quality that libraries, either integrated in the program or to be a part of it, provide to their users.

In the first year of this project, nine teachers were appointed to perform this role; since it was needed to enlarge the areas of intervention of the team, this one was reinforced, in 2005, with more three teachers. This team work is helped by three teachers of the board of educational and technical support from the Educational Region Direction of Lisbon, which rules an area with a wide range of schools.

This team work accompanies a total number of 1402 libraries of different educational levels: $6701^{\text {st }}$ Cycle Schools; $411^{\text {st }}$ and $2^{\text {nd }}$ Cycles Basic Schools; $3932^{\text {nd }}$ and $3^{\text {rd }}$ Cycles Basic Schools and 295 Secondary Schools. In average, each teacher accompanies 14 district subdivisions, except those who work in metropolitan areas since the short number of district subdivisions, in these cases, contrasts with the high number of schools.

Analysing these data according to the typology of schools, and according to the Portuguese Educational System, we can conclude that, in average, each teacher accompanies $451^{\text {st }}$ Cycle Schools; $31^{\text {st }}$, $2^{\text {nd }}$ and $3^{\text {rd }}$ Cycles Basic Schools; $262^{\text {nd }}$ and $3^{\text {rd }}$ Cycles Basic Schools and 20 Secondary Schools ${ }^{\mathrm{vi}}$.

The work developed by these teachers, although mostly centred in schools that belong to the SLN, also includes all schools that aim at being a part of the Program, in accordance with its guidance lines.

The diversity of schools and the complexity of this work imply a continuous accompaniment of the projects of several libraries, which demands from the teachers a wide profile of abilities, in order to really accomplish the different kinds of support they are asked for.

\section{Areas of intervention in the accompaniment of school libraries}

Teachers who accompany and provide support to school libraries have an enlarged profile of abilities, so that they can operate in the following areas:

\section{Area of libraries' integration in schools/groups of schools and in the communitie}

- make management directors aware of the advantages of involving SL team in the 
elaboration of all policy, planning and regulation school documents, such as Educational Project, Inside Regulations, School Curricula Plan and Plan of Activities;

- make teachers, structures of educational guidance, management directors and others to reflect upon the transversality of the role and functions of school libraries inside schools and in the local community;

- alert management directors and teams to the importance of a sustained development of libraries, giving relevance to their informative, educational, cultural and recreational characteristics and articulating libraries' activities with other school dynamics;

- support libraries in what concerns the creation of projects/activities which promote the connection between library and school or community - asking for the presence of external elements, like parents, local associations and others.

\section{Area of network and cooperation}

- make management directors, teams and municipal libraries aware of the advantages of cooperation concerning the sharing of information resources and collections' development; the borrowing and circulation of documents; the common exploration of infra-structures and activities; the organization of activities aimed at the promotion of reading and cultural recreation; the common establishment of actions aimed at promoting literacies and technical / educational qualification and support;

- work together with management directors, teams and municipal libraries in order to create strategies which can lead to the integration of schools of the different educational levels, by means of defining action plans to school libraries that belong to a group of schools, a subdivision of a district or a region;

- alert Educational Councils, teams, Training Centres and upper education establishments, so that they can cooperate with each other in order to analyse qualification needs, direct or indirectly related to the work developed inside school libraries, planning proper qualification actions and using all the possibilities given by schemes of continuous and specialized training in force.

\section{Area of planning, management and evaluation}

- alert management directors and school teams to the need of following the basic principles of the SLN Program related to the creation and/or restructuring of libraries, in accordance with the guidance lines that concerns to:

i. $\quad$ space organization and equipment, according to different uses and services;

ii. the creation of a varied documental fund, including different languages, supports and types, which must be looked after and organized according to library management rules and available to free access, promoting home borrowing;

iii. the creation of a cohesive team to run the library (choosing the supervisor and recruiting the other members - teachers and support staff), according to the abilities profile defined in the Program;

iv. adequate budget provision to support current and investment costs;

- help teams in the creation of different documents concerning planning, regulation and evaluation of library's performance - Activities Plan, Procedures Manual, Collection Development Policy, ... 


\section{Area of documental management, information and marketing}

- contribute to the creation and establishment of a documental and acquisitions policy that can be the basis of significant evolutions related to:

i. $\quad$ the enlargement and variety of documental funds;

ii. the recognition of library's role concerning selection, validation and mediation of documental resources;

iii. the enlargement of library's concept, by means of a wide spread of information, preferably independent from time and space.

- provide teams, together with municipal libraries, with technical and documental support concerning documental management, organization and circulation;

- suggest teams to organize activities, related to users' training, which privilege a proper use of the services and resources provided by school libraries:

i. guided tours to the library, that can be animated with little games or pastimes, specially in the case of younger students;

ii. meetings aimed at teachers and/or students about certain type of services or topics: reading in presence or home reading; reference service, bibliographic circulation, reading guidance, sources of information available in the library, ...;

iii. specific meetings aimed at teachers and/or students to make known and explain how to use certain information or equipment resources - how to consult the library's catalogue, how to use varia documentation, how to present a bibliographic reference, how to use the Internet, ...

- provide teams with proper bibliography and good examples of materials produced to help users, which can promote and make it easier to use library's services and resources: users' guide; library's map with the indication of the different functional areas; guide to use a catalogue; instructions on how to use equipments; general guidance papers to use the different types of information resources available in the library; support material, which can be elaborated in accordance with the new non-subject curricula areas, like study methods and techniques project work; information reports; catalogues and bibliographies on different subjects; new acquisition's lists; selected pointers' lists, ...

\section{Area of curricula, literacy of information and reading promotion}

- contribute to make management directors, structures of educational guidance and teams aware of the library's importance concerning support to curricula, specially after the changes in the organization of schools related to their functioning rules.

The educational role of a SL will be more and more relevant as long as it shows to be able to promote:

i. the accomplishment of a transversal work in articulation with teachers and their teaching practice concerning not only planning, execution and evaluation of teaching activities but also the choice of the most suitable resources to teaching techniques and activities, promoting information abilities;

ii. the cooperation with educational management structures in what concerns the adequacy of curricula and subjects planning, evaluating the most suitable resources to educational innovation and invention; 
iii. the creation of teaching materials and other formative documents which can show the library's potential as an interface of teachers' educational practices modernization;

iv. the inclusion of production and training spaces in the library that promote teachers' participation in library activities and multiply the opportunities given to students to understand the nature of different supports and types of documents, stimulating the formulation of critical judgements about those documents;

v. to involve management structures and teams in the development of coherent initiatives concerning literacy and reading promotion.

\section{Area of educational and documental use of information and communication techniques}

- contribute to make management structures and teams see libraries as general places of information and communication techniques (ICT) use, aiming at a good service quality relation concerning users, namely about:

i. number and updating of searching posts, localization, educational accompaniment, technical support, net structure and electronic services available;

ii. automatic catalogue;

iii. school/SL web page;

iv. use of electronic information resources - online and offline;

v. participation in projects/activities using ICT.

Teachers responsible for school libraries accompaniment must share certain personal abilities, the most important being:

- experience and qualification concerning the areas related to school libraries;

- average general cultural knowledge;;

- motivation, interest and availability in performing their role;

- open spirit towards innovation, leadership abilities, communicative easiness, preference for team work, moderated and good sense attitude concerning the work with third partners, sagacity, pleasure in sharing;

- availability to continuously invest in their own scientific, technical and educational qualification.

Main activities performed by teachers responsible for accompaniment

The role and activities of the teachers responsible for direct accompaniment and support of school libraries are established/articulated together with the Educational Region Direction of their working area, specially aiming at:

- gather information and obtain, through contacts established with schools, municipal libraries and Educational Region Directions, accurate balances in what concerns SLN Program support and possible constraints;

- make visits, in articulation with SLN Cabinet and Educational Region Direction, according to the school net of each area and the number of schools/groups of schools that already belong to the SLN or to integrate it in the future, giving priority to schools recently supported; 
- answer the needs of SLN Cabinet, Educational Region Directions or groups of schools, in order to visit certain schools or undertake specific actions;

- appeal to schools which does not belong to the Program for the presentation of a library creation/development project;

- elaborate support and guidance materials to schools, according to the needs arisen by the contact with teams and management structures;

- give answer to information requests and clarifying doubts presented by schools;

- provide library teams information about subjects of their own interest: projects, contests, training actions, applications, events, ...

- plan activities aimed at alerting teams and management structures to the importance of school libraries or training them;

- cooperate with schools and other partners in what concerns the organization of meetings, seminars or other events related to the activities developed by school libraries;

- elaborate reports and provide Educational Region Direction and SLN Cabinet with regular information about subjects of their own interest, contributing also to the evaluation of SL's performance done by the Ministry of Education - SLN Cabinet;

- identify and reveal good practices examples, namely by publishing documents in the SLN site;

- accompany the role of teams and teachers appointed to work with Primary Schools, specially those who work with more than one SL;

- cooperate with SLN Cabinet, using knowledge and experiences given by daily contact with schools and field work, in what concerns the production and reformulation of training documents;

- promote central, regional or local exchange of knowledge and experiences, sing the distribution list created to accomplish this aim - Direct Line and/or other available means of communication;

- encourage teams to put their bibliographic basis in the SLN user and to promote the import of registry from those basis in order to update their catalogues.

Visits paid to schools originate different types of actions:

- considering that the visit was enough in a first step, providing guidance lines concerning the problems arisen and defining improvement strategies, verifying after if they were taken;

- considering that the study of certain subjects/problems must be deepened by means of undertaking work sessions, or even extending them to other schools of the same area that might s well be interested;

- when planning visits, it is given special attention to work sessions with local partners, namely municipal libraries and, in certain cases, according to the problems arisen, the autarchy, the Schools Association Training Centre and other schools that belong to the same group of schools or area;

- in addition to visits, work meetings and encouraging/training activities with schools or groups of schools, and meetings including other partners, separate contacts with different partners are established, specially in the case of complex situations.

All these actions are used in an isolated or combined way, although they do not exhaust all possible and varied intervention strategies used in daily praxis.

This report aimed at sharing a recent line of action, thus innovator in our context. 
After a brief presentation of SLN Program, its action line and implementation degree, we presented the way we perform school libraries direct accompaniment. We described the team work created, the reality which shapes its intervention areas and the activities developed. According to the reality presented, it is easy to conclude the main nature of the work we aim at developing by providing these libraries with support and accompaniment.

This work necessarily involves an administrative component concerning the verification and validation of the way libraries are working, but, independently from the judgements we might formulate, the most important for us is to be able to define with these libraries strategies that can improve their work and overcome their problems and difficulties, as long as new ideas that can promote their quality growth. In this sense, this work has a strong formative component, according to which we will certainly have many things to learn from schools and vice versa, if we are really able to perform our role, by developing the abilities needed to accomplish it.

The success of School Libraries Network and its impact on teaching and education improvement depends not only upon the contribution of all partners involved in this Program - Central Administration, Educational Region Directions, Town Halls, Public Libraries, Training Centres and other formative entities, but also, in a large measure, upon this team of teachers assigned to work in the field, who, together with schools and their teachers, search for give their contribution to a stronger libraries' efficacy concerning learning progress and literacy levels.

The experience reported is recent and far from allowing a complete evaluation of the results already achieved. Its monitorship by the SLN Cabinet and the feedback we informally get from the schools and partners we work with has been showing the importance of this initiative, and we hope it to become a successful practice concerning SLN and the general work performed all over the world in favour of school libraries' development.

\title{
References
}

Lançar a Rede de Bibliotecas Escolares (1996). Coord. Isabel Veiga. Lisboa, Ministério da Educação.

\author{
Author note: \\ Elsa Maria Conde, member of the board of permanent teachers of Rainha D. Amélia Secondary \\ School. Graduated in History by the Faculty of Arts of Lisbon University. Also graduated in \\ Documental Sciences (Libraries and Documentation) and Master in Multimedia Educational \\ Communication by Open University. \\ She became a member of the team that supervises the Schools Libraries' Network Program in \\ $1997 / 1998$. \\ At present she continues to work within the same Program, and she is assigned to accompany and \\ provide technical support to schools from Lower and Coastal Alentejo. \\ Maria Lucília Marques dos Santos, member of the board of permanent teachers of Avelar Second \\ and Third Cycles Basic. Graduated in History by the Faculty of Arts of Coimbra University. Also \\ graduated in Documental Sciences (Libraries) and studying to be a Master in Information \\ Management and School Libraries from Open University. \\ She has been assigned to the School Libraries' Network Program since 2004, to accompany and \\ provide technical support to schools from the districts of Leiria, Santarém and Castelo Branco.
}


João Manuel S. Afonso, member of the board of permanent teachers of Alcains Secondary and Third Cycle Basic School (Castelo Branco). Graduated in Modern Languages and Literatures Portuguese Studies. Also graduated in Documental Sciences (Libraries).

He has been assigned to the School Libraries' Network Program since 2004, to accompany and provide technical support to schools from the districts of Castelo Branco, Guarda and Portalegre.

José António Videira Saro, member of the board of permanent teachers of Guia Second and Third Cycles School and Secondary School (Pombal). Graduated in Classic Languages and Literatures by the Faculty of Arts of Coimbra University. Master in Classic Languages and Literatures by the Faculty of Arts of Coimbra University. He is studying to be PhD in Métodos de Investigación en Biblioteconomía in Salamanca University.

He has been assigned to the School Libraries' Network Cabinet since 2004, to accompany and provide technical support to schools from the districts of Coimbra and Aveiro.

\footnotetext{
${ }^{\mathrm{i}}$ In Portugal, this program is known as RBE (Rede de Bibliotecas Escolares).

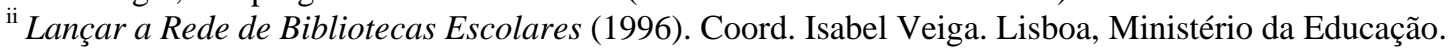

iii Pre-School Education takes place in kindergartens, it is not compulsory and it is intended to children between 3 and 6 years old. Non-University School Education includes Basic and Secondary Education. Basic Education has 3 cycles, and it is universal, compulsory and free. The First Cycle, or Primary Education (1BS) lasts for 4 years (6-10 years old); the Second Cycle (2BS) lasts for 2 years (10-12 years old); and the Third Cycle (3BS) lasts for 3 years (12-15 years). Secondary Education (SE) is not compulsory, it lasts for 3 years (15-18 years old) and integrates general, technical, artistic and professional studies (PS).

${ }^{\text {iv }}$ In Portugal, this service is known as SABE (Serviço de Apoio às Bibliotecas Escolares).

${ }^{\vee}$ In Portugal, these institutions are known as DREs (Direcções Regionais de Educação).

vi The data presented refer to average values, distributed according to the most representative typologies of schools. We present below the data referring to the total number of schools supported:
}

\begin{tabular}{|c|c|c|c|c|c|c|c|c|}
\hline $1 \mathrm{BS}(\mathrm{PS})$ & $2 \mathrm{BS}$ & $\mathrm{P} / \mathrm{BS}$ & $2 \mathrm{BS}$ & $2 / 3 \mathrm{~B} / \mathrm{SS}$ & $3 \mathrm{~B} / \mathrm{SS}$ & $\mathrm{SS}$ & $\mathrm{PS}$ & Total Schools \\
\hline 670 & 10 & 41 & 359 & 24 & 220 & 75 & 3 & 1.402 \\
\hline
\end{tabular}


Reproduced with permission of the copyright owner. Further reproduction prohibited without permission. 